\title{
Serum Selenium Level in Patients with Chronic Liver Disease
}

\author{
Ghada M. Galal*, Nagwa S. Ahmed**, Asmaa N. Mohammad*, Rahma S. Bakrey* \\ Department of Tropical Medicine and Gastroenterology* and Department of Medical \\ Biochemistry** Sohag Faculty of Medicine, Sohag University, Egypt.
}

\begin{abstract}
Background: Selenium has been shown to protect against liver necrosis. Selenium deficiency has been involved in the pathogenesis of chronic hepatitis B and C related hepatocellular damage.Serum selenium concentration in cirrhotics was found tobe low, supportive selenium administration may be beneficial for them.Reduced selenium levels result in accumulation of lipid peroxides which accelerate the growth of hepatocellular carcinoma (HCC).

Aim: To study serum selenium level in patients with chronic liver diseases and its relation with severity of theliver diseases.

Patients and Methods: This case-control study was conducted on 100 subjects. The cases were $\mathbf{8 0}$ adult patients including chronic hepatitis $\mathrm{C}$ and $\mathrm{B}$, liver cirrhosis and HCC.The study also included 20 healthy age and sex-matched subjects served as a control group. Clinical, laboratory and radiological data and blood samples were collected from all participants. Serum selenium concentration was measured and statistical analysis was done.

Results: Selenium concentration was significantly lower in patients compared to healthy controls.Selenium levelwas found low in Chronic HBV, chronic HCV patients and lower incirrhotic group and the lowest in HCC group. Patients with advanced liver cirrhosis (Child $\mathrm{B}, \mathrm{C}$ ) had significantly lower selenium level compared to those with Child A.

Conclusion: Selenium was lower in patients with chronic liver disease and its leveldecreases with the progression of liver disease. Patients with HCC had the lowest Selenium concentration that might correlate with the pathophysiology of HCC. Chronic hepatitis $\mathrm{C}$ and $\mathrm{B}$, liver cirrhosis and $\mathrm{HCC}$ were independent predictors forSelenium deficiency.
\end{abstract}

\section{Introduction}

Selenium (Se) is an essential trace element for humans. It is the essential component of several major metabolic pathways, being the constituent of human selenoproteins(Burk, 2002). The most important and known action is its antioxidant effect because it forms selenocysteine, part of the active center of the glutathione peroxidase (GSH-Px) enzyme (Navarro-Alarcon et al., 2000).

Selenium deficiency induces some pathological conditions, such as cancer, coronary heart disease, and liver necrosis (Yoshiro et al., 2003). Selenium is an essential trace mineral that is a component of major antioxidant enzymes, selenoproteins (glutathione peroxidase, thioredoxinreductase). Glutathione peroxidase is responsible for detoxification in the body by reducing peroxide free radicals that include lipid peroxide formation in cell membranes. (Stranges et al.,2010)

Selenium has been shown to protect against dietary liver necrosis, its selenoenzyme glutathione peroxidase protects the bio membranes from oxidative destruction, and the decreased level of this enzyme increases the tendency of cellular damage (Leccia et al., 1995).

Serum selenium concentration in cirrhotics was found tobe low, supportive selenium administration may be beneficial (Burk, 2002).Selenium deficiency has been involved in the pathogenesis of chronic hepatitis $B$ and $C$ through progressive immune dysfunction effects, resulting impairment of the activities of 
leucocytes, neutrophil, and macrophages (Spallholz et al., 1990).

Epidemiological studies have shown that low grain selenium content is associated with a high regional incidence of hepatitis B viral infections (Yu YS et al., 1989). Selenium deficiency has been involved in the pathogenesis of a number of clinical findings in chronic liver diseases. The protective role of selenium against hepatitis was reported first in 1997. Different studies have shown lower concentration of selenium in the serum and erythrocytes of hepatitis B and C patients (Platis et al., 2004).

The deficiency of selenium is common in patients with hepatitis due to poor appetite during infection, decrease in intake and absorption, decreased bioavailability, and increased lossesbecause of mal absorption(Raufet al., 2012).

Reduced selenium levels result in accumulation of lipid peroxides. This leads to enhanced AP-1 activation and consequently to elevated expression of VEGF and IL-8, which accelerate the growth of HCC (Jiang $\mathbf{C}$ et al., 2000).

\section{Aim of the work}

To study the level of serum selenium in patients with chronic liver disease and its relation with severity of chronic liver diseases.

\section{Patients And Methods}

In order to study the level of serum selenium in patients with chronic liver diseases compared to healthy controls and to study the relationship between serum selenium concentration and severity of liver cirrhosis we conducted this casecontrol study on $\mathbf{1 0 0}$ subjects.

\section{Study population:}

Our study included 80 adult patients attending the out patients clinic and /or admitted to the inpatient section of the Department of Tropical Medicine and Gastroenterology, Sohag University Hospital.

The patients were categorized to four groups:The first group included fifteen patients with chronic hepatitis C.The second group included fifteen patients with chronic hepatitis B.Thirty patients with liver cirrhosis are included in the third group. The fourth group included twenty patients with HCC.The study also included 20 healthy age and sex-matched subjects with no clinical, laboratory or ultrasonographic evidence of liver disease served as a control group.

Exclusion criteria:We excluded the following patients from the study:

1. Patients who are receiving selenium supplementation.

2. Patients who are receiving or received antiviral treatment for hepatitis B or C.

3. Patients with hematocrit value less than $25 \%$.

4. Patients with coronary heart diseases and cancers other than HCC.

5. Patients suffering from any other comorbidy.

The study protocol was approved by the local Ethics Committee of Sohag Faculty of Medicine. All patients and controls included in the study signed a written informed consent before starting data collection with respect to patients' confidentiality.

Methods: All participants and controls are subjected to the following:

I-History Taking:Includes: age, sex, special habits (smoking, alcohol intake), address (because some areas are deficiency), etiology of liver cirrhosis, symptoms of liver cell failure and portal hypertension. History suggesting presence of other significant co morbid conditions will be recorded.

II- Clinical Examination:Includes: vital signs, general, systemic and examination abdominal examination with stress on presence of organomegaly, manifestations of portal hypertension, manifestations of liver cell failure, manifestations suggesting spontaneous bacterial peritonitis andmanifestations suggesting other organ failure.

III- Laboratory Investigations including: Complete blood picture (CBC), Liver profile: serum bilirubin, serum 
albumin, liver enzymes, prothrombin time and concentration, international normalization ratio (INR) and Serology for hepatitis C and hepatitis B (HCV- Abs and HBsAg). Serum creatinine, random blood sugar and urine analysis also were done. Ascetic fluid study in patients with ascites and Alpha fetoprotein were done.

\section{IV- Imaging:}

a) Abdominal Ultrasonography was done with stress on:size of the liver, surface, echo pattern, hepatic focal lesion, portal vein diameter.Size of the spleen, splenic vein diameter, portosystemic collaterals.Presence or absence of ascites.

b) Tri phasic abdominal C.T and / or MRI for diagnosis of $\mathrm{HCC}$.

V- Liver prognostic indicators were calculated by Child-Turcotte-Pugh (CTP) score (Child and Turcotte, 1964; Pugh et al., 1973).

VI- Blood Samples and Method of Measurement of Selenium:

Blood samples were collected from all participants. Serum was immediately separated using centrifugation, aliquoted, stored at $-\mathbf{2 0}^{\circ} \mathbf{C}$ and thawed only at the time of the assay.Serum selenium concentration was measured using Selenium Kits (ABC Diagnostic Egypt) by colorimetric method.

\section{Statistical analysis:}

Data were analyzed using STATA intercooled version 12.1. Quantitative data were represented as mean, standard deviation, median and range. Data were analyzed using student t-test to compare means of two groups and ANOVA for comparison of the means of three groups or more. When the data were not normally distributed Kruskal Wallis test for comparison of three or more groups and Mann-Whitney test was used to compare two groups. Qualitative data were presented as number and percentage and compared using either Chi square test or fisher exact test. Multivariate linear regression was done to determine the factors affecting selenium concentration and absorbance. Graphs were produced by using Excel or STATA program. P value was considered significant if it was less than $\mathbf{0 . 0 5}$.

\section{Results}

The mean age of our studied patients was $\mathbf{4 1 . 1 6} \pm \mathbf{1 2 . 8 7}$ years, $\mathbf{6 8 . 8 \%}$ of them were males. Our results showed that mean serum Selenium concentration was significantly lower in the studied cases compared to control group as showed in table (1).

Mean serum Selenium concentration was significantly lower in patients compared to healthy controls $(\mathbf{4 3 . 3 4} \pm \mathbf{1 1 . 4 1}$ versus $84.45 \pm \mathbf{1 1 . 8 5}, \mathrm{P}$ value $=<\mathbf{0 . 0 0 0 1})$. It was also significantly lower in each of the studied groups (chronic hepatitis $\mathrm{C}$, chronic hepatitis $\mathrm{B}$, liver cirrhosis and HCC) when compared with healthy controls ( $\mathrm{P}$ value $<\mathbf{0 . 0 0 0 1}$; < $\mathbf{0 . 0 0 0 1}$; $<0.0001$; $<0.00001$ respectively). However no significant difference was found in mean serum selenium between patients with chronic hepatitis $\mathrm{B}$, chronic hepatitis $\mathrm{C}$, and liver cirrhosis. Patients with HCC had significantly lower selenium level when compared to other groups (table 2).

There was significant lower selenium concentration in patients with jaundice, ascites, bleeding tendency and hepatic encephalopathy in comparison to control group ( $\mathrm{P}$ value $\mathbf{0 . 0 0 0 1 , 0 . 0 0 0 8 , 0 . 0 0 0 1}$ and 0.0001 respectively). 
Figure (1): Relationship between Selenium concentration and Child score

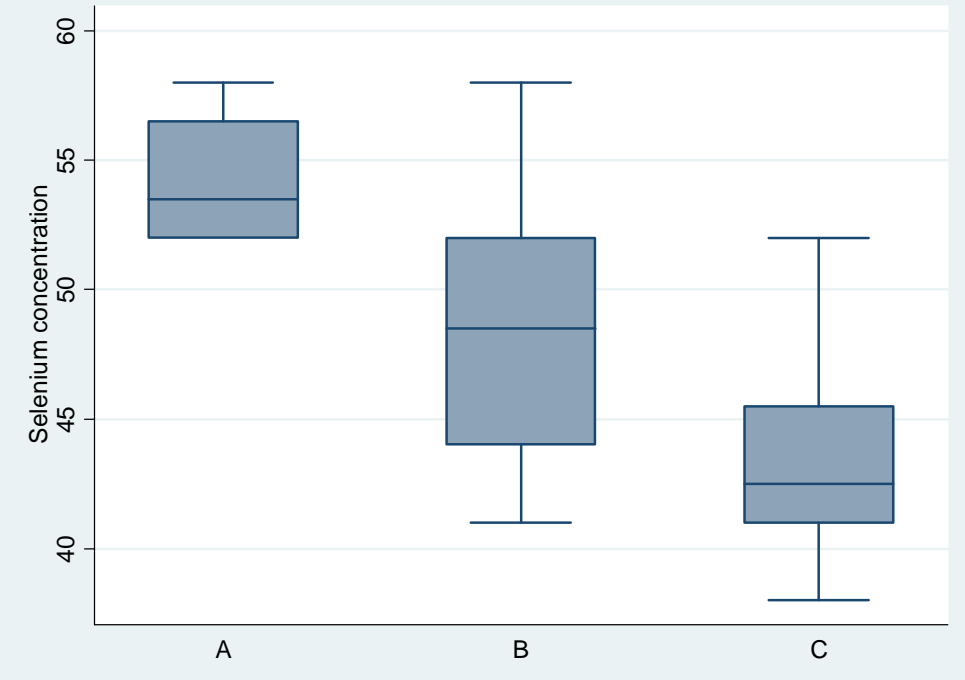

Table (1): Selenium concentration of study populations (case - control)

\begin{tabular}{|l|l|l|l|}
\hline Variable & Controls & Cases & P value \\
\hline $\begin{array}{l}\text { Selenium concentration } \\
\text { Mean } \pm \text { SD }(\mu \mathrm{g} / \mathrm{L})\end{array}$ & $\mathbf{8 4 . 4 5} \pm \mathbf{1 1 . 8 5}$ & $\mathbf{4 3 . 3 4} \pm \mathbf{1 1 . 4 1}$ & $<\mathbf{0 . 0 0 0 1}$ \\
\hline
\end{tabular}

Table (2): Comparison of serum selenium in the studied groups

\begin{tabular}{|c|c|c|c|c|c|}
\hline Variable & \begin{tabular}{|l|}
$\begin{array}{l}\text { Controls } \\
(\mathbf{n}=\mathbf{2 0})\end{array}$ \\
\end{tabular} & $\begin{array}{l}\text { Chronic } \\
\text { HBV } \\
=15)\end{array}$ & $\begin{array}{l}\text { Chronic } \\
\text { HCV } \\
(n=15)\end{array}$ & \begin{tabular}{|l} 
Liver \\
cirrhosis \\
$(\mathbf{n}=\mathbf{3 0})$
\end{tabular} & $\begin{array}{l}\text { HCC } \\
(n=20)\end{array}$ \\
\hline $\begin{array}{l}\text { Selenium } \\
\text { concentration } \\
\text { Mean } \pm \text { SD } \\
(\mu \mathrm{g} / \mathrm{L})\end{array}$ & $84.45 \pm 11.85$ & $46.47 \pm 7.03$ & $49.73 \pm 9.55$ & $47.9 \pm 6.19$ & $29.35 \pm 9.98$ \\
\hline P vs. controls & & $<0.0001$ & $<0.0001$ & $<0.0001$ & $<0.00001$ \\
\hline P vs. HBV & $<0.0001$ & & 1.00 & 1.00 & $<0.0001$ \\
\hline P vs. HCV & $<0.0001$ & 1.00 & & 1.00 & $<0.0001$ \\
\hline P vs. LC & $<0.0001$ & 1.00 & 1.00 & & $<0.0001$ \\
\hline P vs. HCC & $<0.0001$ & $<0.0001$ & $<0.0001$ & $<0.0001$ & \\
\hline
\end{tabular}


Table (3): Univariate regression analysis of factors affecting Selenium concentration

\begin{tabular}{|c|c|c|}
\hline Variable & $\begin{array}{l}\text { Regression coefficient } \\
(95 \% \quad \text { confidence } \\
\text { interval) }\end{array}$ & $P$ value \\
\hline $\begin{array}{l}\text { Group } \\
\text { HBV } \\
\text { HCV } \\
\text { LC } \\
\text { HCC } \\
\end{array}$ & $\begin{array}{l}-39.78(-46.29:-33.28) \\
-34.25(-40.77:-27.73) \\
-46.24(-69.92:-22.56) \\
-71.10(-95.15:-47.06)\end{array}$ & $\begin{array}{l}<0.0001 \\
<0.0001 \\
<0.0001 \\
<0.0001 \\
\end{array}$ \\
\hline $\begin{array}{l}\text { Child score } \\
\text { A } \\
\text { B } \\
\text { C } \\
\end{array}$ & $\begin{array}{l}13.75(-3.37: 30.87) \\
5.71(-3.75: 15.16) \\
12.22(-2.24: 28.72)\end{array}$ & $\begin{array}{l}0.12 \\
0.23 \\
0.11\end{array}$ \\
\hline Jaundice & $7.08(-0.67: 14.83)$ & 0.07 \\
\hline Ascites & $8.28(-1.33: 17.91)$ & 0.09 \\
\hline Bleeding tendency & $-6.11(-13.16: 0.94)$ & 0.09 \\
\hline $\begin{array}{l}\text { Hepatic } \\
\text { encephalopathy }\end{array}$ & $0.90(-6.54: 8.34)$ & 0.81 \\
\hline Hematemesis & $-0.98(-7.50: 5.54)$ & 0.77 \\
\hline Total bilirubin & $-0.14(-4.73: 4.44)$ & 0.95 \\
\hline ALT & $0.11(-0.03: 0.25)$ & 0.13 \\
\hline AST & $-0.03(-0.13: 0.06)$ & 0.68 \\
\hline Albumin & $0.14(-4.86: 5.14)$ & 0.96 \\
\hline PC & $0.04(-0.20: 0.28)$ & 0.74 \\
\hline AFP & $0.01(-0.006: 0.02)$ & 0.31 \\
\hline HB & $-0.34(-1.85: 1.16)$ & 0.65 \\
\hline PLTs & $-0.02(-0.07: 0.03)$ & 0.49 \\
\hline
\end{tabular}

Table (4): Final model of multivariate regression analysis of factor affecting Selenium concentration

\begin{tabular}{|c|c|c|}
\hline Variable & $\begin{array}{l}\text { Regression coefficient } \\
(95 \% \quad \text { confidence } \\
\text { interval) }\end{array}$ & P value \\
\hline Group & & \\
\hline HBV & $\begin{array}{l}-38.33(-44.46:-32.21) \\
-34.72(-40.80 \cdot-2863\end{array}$ & $\begin{array}{l}<0.0001 \\
<00001\end{array}$ \\
\hline HCV & $-34.72(-40.80:-28.63)$ & $<0.0001$ \\
\hline $\begin{array}{l}\text { LC } \\
\mathrm{HC}\end{array}$ & $\begin{array}{l}-37.01(-45.58:-28.43) \\
-56.38(-65.79:-46.96)\end{array}$ & \begin{tabular}{|l|}
$<0.0001$ \\
$<0.0001$
\end{tabular} \\
\hline HC & $-56.38(-65.79:-46.96)$ & \\
\hline
\end{tabular}

Patients with advanced liver cirrhosis (Child B, C) had significantly lower selenium level compared to those with Child A ( $\mathrm{P}$ value $<\mathbf{0 . 0 0 0 1}$ ) figure (1). 
The results showed significant negative correlations between serum selenium level and each of total bilirubin, prothrombin time, AFP and liver enzymes. On the other hand, there were significant positive correlations between serum selenium level and each of serum albumin, prothrombin concentration, hemoglobin level and platelet count.

Multivariate regression analysis for the all significant variables in univariate analysis showed that the presence of chronic HBV, chronic HCV, liver cirrhosis and or HCC found to be independent risk factors for low serum selenium level table $(\mathbf{3}, \mathbf{4})$.

\section{Discussion}

Selenium is essential trace element integrates into selenoproteins that have antioxidant and anti-inflammatory effects. Higher selenium status or selenium supplementation has also shown to have antiviral effects (Rayman, 2012). Moreover, selenium is an active immunomodulator, much more potent antioxidant than vitamins $\mathrm{A}, \mathrm{C}, \mathrm{E}$ and betacarotene (Ozardali et al., 2004).In the 1960s and 1970s epidemiological data began to demonstrate that selenium also possesses anti-carcinogenic activity (Murray, 1996).

We conducted this research in order to study serum selenium level in patients with chronic liver diseases compared to healthy controls and to study the relationship between serum selenium concentration and severity of liver cirrhosis.We found no significant differences as regard gender and age factors in the studied groups, as had previously been observed in healthy subject (Navarro et al., 1995).

According to our results there was a significant decrease observed in serum selenium in patients with chronic hepatitis (chronic HBV and chronic HCV) in comparison to healthy controls. Different studies have shown same results in chronic hepatitis B and C patients. They found that the deficiency of selenium is common in patients with hepatitis and this was explained by the poor appetite during infection, decrease in intake and absorption, decreased bioavailability, and increased losses because of malabsorption(Zhang et al., 1999; Stehbens, 2004 and Rauf et al., 2012). Another survey demonstrated an inverse association between selenium level and hepatitis B virus infection (Yu et al., 1997).

Mean serum Selenium concentration in our study was significantly lower in cirrhotic patients compared to healthy controls agree with Al-Bader et al. (1998) who observed a significant decrease of plasma selenium levels accompanied by liver cirrhosis after givinghighest thioacetamide. These changes were confirmed to be due to selenium deficiency caused by thioacetamide, as supplementation with this element reversed them.

Multiple previous studies have shown the same results with a significant decrease of plasma and serum selenium levels in patients with liver cirrhosis (Buljevac et al., 1996; Al- Bader et al., 1998 and Burk et al., 2015). Against our results in cirrhotic patients Burk et al. (1998) observed that concomitantly to impairment in plasma selenium, an increase in plasma GSH-Px activity was established. Their finding suggests that patients with cirrhosis may not have selenium deficiency.

According to the current study, significantly lower serum selenium concentration was found in patients with HCC when compared to the other groups. Rohr-Udilova et al. (2012) showed that reduced Selenium levels and the subsequent reduced oxidative capacity lead to the accumulation of lipid peroxides producing reactive oxygen species (ROS) in patients with HCC. They set out to determine the effect of low Se levels on vascular endothelial growth factor (VEGF) and interleukin 8 (IL-8) expression, both 
of which are crucial in the development and growth of HCC. Interestingly, they found that Se levels correlated inversely with VEGF and IL-8 levels and also with tumor size in small HCC nodules. This finding is in agreement with previous studies showing that patients with chronic viral hepatitis and HCC had significantly lower Se plasma levels compared to those without HCC (Yu et al., 1999 and Lin et al., 2006). Against our results Buljevac et al. (1996) did not find significant differences in serum selenium concentrations in patients with liver cirrhosis vs. those with liver cirrhosis and coexistent HCC.

Our result showed that serum Selenium was significantly decreased with signs of hepatic decompensation namely (jaundice, ascites, hepatic coma, and bleeding tendency) than without. Accordingly we found that patients with advanced liver disease (Child score B-C) had significantly lower serum Selenium concentrations than patients with compensated liver disease (Child score A). Similar results were found by previous studies, they postulated that serum selenium levels decreased as the disease advanced, reached the lowest level in the final stages (Dworkin et al., 1985 and Conri et al., 1988). These findings effectively confirm that the severity of the liver injury is one of the factors conditioning the impairment in the Selenium body status observed in patients with chronic liver disease.

Considering multivariate regression analysis for the all significant variables in univariate analysis showed that the presence of chronic $\mathrm{HBV}$, chronic $\mathrm{HCV}$, liver cirrhosis and / or HCC are independent risk factors for low serum selenium level. These findings agree with Conri et al., 1988; Yu et al., 1999; Stehbens, 2004 and Lin et al., 2006).

Some researchers have indicated that impaired selenium status found in individuals with liver diseases could be ameliorated by selenium supplementation (Buljevac et al., 1996; Al- Bader et al.,
1998 and Martinez et al., 2010). Therefore, we believe that the possible prophylactic use of this element against increase in the severity of chronic liver disease should not be discarded and, therefore, should be subject of future research.

In conclusion serum selenium levels were significantly lower in patients with chronic liver disease than in healthy control group. Also, Serum Selenium levels significantly decreased in relation to the progression of chronic liver disease. Patients with HCC had the lowest serum Selenium concentration that might correlate with the pathophysiology of HCC. Chronic hepatitis $\mathrm{C}$ and $\mathrm{B}$, liver cirrhosis and HCC were independent predictors of selenium deficiency.

\section{References}

1. Al-Bader A, Abul H, Hussain T, AlMoosawi M, Mathew TC and Dashti $H$ (1998): Selenium and liver cirrhosis. Mol Cell Biochem;185: 1-6.

2. Buljevac $M$, Romiyc $Z$, Vuceliyc B, Baniyc $M$, Krznariyc $Z$ and Pleysco $S$ (1996): Serum selenium concentration in patients with liver cirrhosis and hepatocellular carcinoma. Acta Med Croatica; 50: 11-14.

3. Burk RF (2002): Selenium, an antioxidant nutrient. NutrClin Care 5: 75-9.

4. Burk RF, Early DS, Hill KE, Palmer IS and Boeglin ME (1998): Plasma selenium in patients with cirrhosis. Hepatology; 27: 794-798.

5. Burk RF, Hill KE (2015): Regulation of selenium metabolism and transport. Annu Rev Nutr;35:109-34

6. Chappuis $P$ and Poupon J (1991): Le role de selenium dans la defense du stress oxidative. CahNutr Diet; 26: 295-297.

7. Conri C, Fleury B, Simonoff M, Ducloux G, Berden B and MorettoP (1988): Selenium zinc et cuivreserique au cours de l'alcoholisme. Ann Med Int; 139: 138-139.

8. Dworkin B, Rosenthal WS, Jankowski RH, Gordon GG and HaldeaD (1985): Low blood selenium levels in alcoholics 
with and without advanced liver disease: correlation with clinical and nutritional status. Dig Dis Sci; 30: 838-844.

9. Ha HL, Shin HJ, Feitelson MA and Yu DY (2010): Oxidative stress and antioxidants in hepatic pathogenesis. World J Gastroenterol28; 16(48): 603560428.

10. Jiang $C$, Ganther $H$ and $L u ~ J$ (2000):Monomethyl selenium-specific inhibitionof MMP-2 and VEGF expression: implications for angiogenic switchregulation. MolCarcinog ;29:236250.

11. Leccia NT, Richard MJ, Beani JC, Faure H, Monjo A M, Cadet J, Amblard $P$ and Favier A (1993): Protective effect of selenium and zinc on UV-A damage in human skin. PhotochemPhotobiol 58:548-553.

12. Lin CC, Huang JF, Tsai LY, Huang YL (2006): Selenium, iron, copper, and zinc levels and copper-to-zinc ratios in serum of patients at different stages of viral hepatic diseases. Biol Trace Elem Res;109 (1): 15-24.

13. Martinez- Peinado $M$, NoguerasLópez F, Arcos-Cebrián A, Agil A and Navarro-Alarcón M (2010): Serum selenium levels in cirrhotic patients are not influenced by the disease severity index. Nutr Res 3(8):574-578

14. Murray M (1996): Selenium. The Encyclopedia of nutritional supplements; 44-53.

15. Navarro M, López H, Ruiz ML, González S, Pérez V, López MC (1995): Determination of selenium in serum by hydride generation atomic absorption spectrometry for calculation of daily dietary intake. Sci Total Environ. 15;175(3):245-52

16. Navarro-Alarcon $M$ and LopezMartinez MC (2000): Essentiality of selenium in the human body: relationship with different diseases. Sci Total Environ; 249: 347-371.

17. Ozardali I, Bitiren M, Karakilçik AZ, Zerin M, Aksoy N, Musa D (2004) : Effects of selenium on histopathological and enzymatic changes in experimental liver injury of rats. ExpToxicolPathol.; $56(1-2)$ : 59-64 .

18. Rauf N, Tahir S, Dilawar S, Ahmad I and Parvez $S$ (2012): Serum Selenium Concentration in Liver Cirrhotic Patients Suffering from Hepatitis B and C in Pakistan. Biol Trace Elem Res 145:144150.

19. Rayman MP (2012): Selenium and human health. Lancet. Mar 31;379 (9822): 1256-68

20. Rohr-Udilova N, Sieghart W, Eferl R, Stoiber D, Bjorkhem-Bergman L, Eriksson LC, Stolze K, Hayden H, Keppler B, Sagmeister S, GraslKraupp B, Schulte-Hermann R, PeckRadosavljevic M (2012): Antagonistic effects of selenium and lipid peroxides on growth control in early hepatocellular carcinoma. HEPATOLOGY; 55: 11121121

21. Spallholz JE, Boylan LM and Larsen HS (1990): Advances in understanding selenium's role in the immune system. Ann N Y AcadSci 587:123-139

22. Stehbens WE (2004): Oxidative stress in viral hepatitis and AIDS. Exp. Mol. Pathol.; 77(2): 121-32.

23. Stranges S, Navas-Acien A, Rayman MP and Guallar E (2010): Selenium status and cardiometabolic health: state of the evidence. NutrMetabCardiovasc Dis. Dec;20(10):754-60

24. Yoshizawa K, Ascherio A, Morris JS, Stampfer MJ, Giovannucci $\mathrm{E}$ and Baskett CK (2003): Prospective study of selenium levels in toenails and risk of coronary heart disease in men. Am. J. Epidemiol.; 158(9): 852-60.

25. Yu MW, Horng IS, Hsu KH, Chiang YC, Liaw YF and Chen CJ (1999): Plasma selenium levels and risk of hepatocellular carcinoma among men with chronic hepatitis virus infection. Am J Epidemiol;150: 367-374.

26. Yu SY, Zhu YJ and Li WG (1997): Protective role of selenium against hepatitis B. Bio Trace element Res; 56(1): 117-124. 
27. Zhang W, Ramanathan CS, Nadimpalli RG, Bhat AA, Cox AA and

Taylor EW (1999): Selenium-dependent glutathione peroxidase modules encoded by RNA viruses. Biol. Trace Elem. Res.; 70: 97-116. 